\title{
Effect of the IGF-1/PTEN/Akt/FoxO signaling pathway on the development and healing of water immersion and restraint stress-induced gastric ulcers in rats
}

\author{
PAN HUANG ${ }^{1}$, ZHENGRONG ZHOU $^{1}$, HAO WANG $^{1}$, QUANWEI WEI ${ }^{1}$, LIANG ZHANG $^{1}$, \\ XIN ZHOU ${ }^{1}$, REINHOLD J. HUTZ ${ }^{2}$ and FANGXIONG SHI ${ }^{1}$ \\ ${ }^{1}$ College of Animal Science and Technology, Nanjing Agricultural University, Nanjing 210095, P.R. China; \\ ${ }^{2}$ Department of Biological Sciences, University of Wisconsin-Milwaukee, Milwaukee, WI 53201, USA
}

Received March 26, 2012; Accepted May 24, 2012

DOI: 10.3892/ijmm.2012.1041

\begin{abstract}
Insulin-like growth factor 1 (IGF-1) and Akt [also known as protein kinase $\mathrm{B}$ (PKB)] proteins have been reported to exhibit gastroprotective effects by reducing water immersion and restraint stress (WRS)-induced gastric mucosal cellular apoptosis. To confirm whether the IGF-1/PTEN/Akt/ FoxO signaling pathway is effective in protecting against gastric ulcers, our current study was conducted to examine the expression and localization of IGF-1, phosphatase and tensin homologue deleted on chromosome 10 (PTEN), Akt and $\mathrm{O}$ subfamily of forkhead box (FoxO) proteins, caspase-3 activity and the number of apoptotic cells in gastric mucosa of rats subjected to WRS. Our results demonstrated that WRS induced gastric ulcers by enhancing cell apoptosis in rat gastric mucosa. In addition, in normal rat gastric mucosa, PTEN, total Akt and FoxO1 were found mainly in the cell cytoplasm of fundic glands in the lamina propria close to the muscularis mucosa. In addition, strong staining of IGF-1, FoxO3a and FoxO4 in the gastric mucosa was primarily concentrated in the cell cytoplasm of the fundic glands in whole lamina propria. However, in rat gastric ulcers, IGF-1, total Akt, FoxO3a and FoxO4 were localized in proximity to the base of the ulcer margin and were also present in the granulation tissues of the gastric ulcers. Moreover, in the rat gastric ulcers, the mRNA transcript levels of IGF-1, PTEN, Akt-1, Akt-2, FoxO3 and FoxO4 were upregulated in the gastric ulcer margin, with a peak between Days 4 and 8 following 7 h of WRS. In conclusion, our results imply that the IGF-1/PTEN/Akt/FoxO signaling pathway plays a certain role(s) in the protection against ulceration through the regulation of cellular apoptosis as observed in the development and healing of rat gastric ulcers.
\end{abstract}

Correspondence to: Professor Fangxiong Shi, Laboratory of Animal Reproduction, College of Animal Science and Technology, Nanjing Agricultural University, Weigang 1, Nanjing 210095, P.R. China

E-mail: fxshi@njau.edu.cn

Key words: insulin-like growth factor 1, O subfamily of forkhead box, signaling pathway, gastric ulcer, rat

\section{Introduction}

The IGF-1/PTEN/Akt/FoxO signaling pathway exerts important physiological effects on many types of animal cells (1-3). Transduction of signals through the insulin-like growth factor 1 (IGF-1) receptor triggers a multiple series of intracellular phosphorylation events as well as those activating several signaling pathways which prevent cell death (4). The phosphatidylinositol 3-kinase (PI3K)/Akt pathway predominantly activated by IGF-1 is a strong cell survival cascade. Akt [also called protein kinase $\mathrm{B}$ (PKB)] is a serine/threonine protein kinase downstream of PI3K (5) and is an important regulator of cell proliferation, cell growth and cell survival (6). To date, three members of the Akt family have been isolated: Akt-1, Akt-2 and Akt-3. Although they are products of different genes, they are closely related to one another, with $>80 \%$ amino acid sequence identity. The three genes are expressed differentially, with a broader expression for Akt-1 and Akt-2 and a more restricted expression for Akt-3 (7). Phosphatase and tensin homologue deleted on chromosome 10 (PTEN) is a tumor-suppressor gene which encodes a dually specific phosphatase that recognizes both lipid and peptide substrates, including phosphatidylinositol $(3,4,5)$-trisphosphate (PIP3), a product of PI3K. Through its lipid phosphatase activity, PTEN controls Akt signaling and its downstream targets responsible for cell size, cell migration, cell cycle, cell death and focal adhesion formation (8). A downstream target of IGF-1/PTEN/Akt signaling is the O subfamily of forkhead box (FoxO) proteins, which is phosphorylated and thereby inhibited by activated Akt (9). Four members, FoxOs, FoxO3a, FoxO1, FoxO4 and FoxO6, have been reported in mammalian cells (10). Phosphorylation of FoxO proteins by Akt results in cytoplasmic retention and inactivation, and consequently inhibits the expression of FoxO-regulated genes which control the cell cycle, cell death and cell metabolism. The shuttling of FoxO between the cytoplasm and nucleus is a key step of cell apoptosis (11).

The water-immersion-and-restraint-stress (WRS) rat has consistently been used as an animal model of gastric mucosal lesions (12-16). Previous studies have reported that activated neutrophils are critically involved in the develop- 
ment and healing of WRS-induced gastric mucosal injury (17). In addition, the gastrointestinal tract has been identified as one of the most sensitive target tissues for IGF-1, which is responsible for various important biological functions, including promotion of the differentiation of various cell types and potent anti-apoptotic activity (4). It has been reported that reperfusion-induced hepatic apoptosis may be reduced by increasing IGF-1 production (18). IGF-1 has also been shown to reduce tissue injury through prevention of cell death in animal models of renal ischemia/reperfusion (I/R) (19). Among the various activities of IGF-1, its anti-apoptotic activity has been shown to play an important role in the reduction of I/R-induced tissue injury by attenuating inflammatory responses $(18,19)$. In particular, previous studies demonstrated that gastric ulceration triggered an $\sim 3$-fold increase in IGF-1 expression in epithelial cells of the ulcer margin. The upregulation of IGF-1 in the gastric ulcer margin accelerated gastric ulcer healing by promoting cell re-epithelialization, proliferation and COX-2 expression via the PI3K pathway $(17,20,21)$. Furthermore, it was reported that IGF-1 reduced WRS-induced gastric mucosal injury by inhibiting gastric accumulation of neutrophils through inhibition of caspase-3 activation by PI3K/Akt signaling (22). Our previous studies demonstrated the cell-specific and age-dependent expression patterns of FoxO4 and FoxO3a proteins in the duodenum, and some involvement in the development and growth performance of the rat duodenum (23). We also found that FoxO4 is a primary forkhead transcriptional factor localized in the gastrointestinal tracts of the pig (24).

The aim of the present study was to determine whether the IGF-1/PTEN/Akt/FoxO signaling pathway is involved in the protection against gastric ulcers. In the rat gastric-ulcer model, we analyzed the expression and localization of IGF-1, PTEN, Akt and FoxO by immunohistochemistry and real-time polymerase chain reaction (PCR), respectively. In addition, we detected cell apoptosis through the TUNEL method and the measurement of caspase-3 activity.

\section{Materials and methods}

WRS-induced gastric mucosal lesion formation in rats. All experiments were carried out on intact male Sprague-Dawley rats (9-11 weeks old; Qinglongshan Experimental Animal Breeding Farm, Nanjing, China), weighing 200-220 g. All procedures were designed in accordance with accepted ethical standards for animal experimentation and the guidelines established by the Institutional Animal Care and Use Committee, Nanjing Agricultural University. Uniform commercial diets used in the experiment were also purchased from Qinglongshan Experimental Animal Breeding Farm. Regular rat chow and tap water were allowed ad libitum. Rats were housed individually at room temperature $\left(25^{\circ} \mathrm{C}\right)$ with a 12:12 h light/dark cycle and humidity of $65-70 \%$. Before each experiment, animals were deprived of food but not water for $24 \mathrm{~h}$. The animals were then placed in a restraint cage and immersed in a water bath $\left(20 \pm 2^{\circ} \mathrm{C}\right)$ to the level of the xiphoid process as described previously (12). Some animals were sacrificed after 3 and $7 \mathrm{~h}$ of WRS, and the rest were normally fed starting $1 \mathrm{~h}$ later and sacrificed at various time points (4, 8 and 15 days) after $7 \mathrm{~h}$ WRS. The animals were anesthetized by an intraperitoneal injection of ether. Their stomachs were removed and filled with $2 \mathrm{ml}$ of $1 \%$ formalin and immersed in $1 \%$ formalin for $24 \mathrm{~h}$. The stomachs were then cut along the greater curvature and examined for mucosal lesions. Since most gastric mucosal lesions were linear and almost always $<2 \mathrm{~mm}$ wide, the total length $(\mathrm{mm})$ of each linear hemorrhagic erosion was measured as the ulcer index (UI) (mm) by an independent observer blinded to the previous treatment, as previously described (25).

Assessment of apoptotic cell number. The sections were rehydrated as described above, and the terminal deoxynucleotidyl transferase UTP nick-end labeling (TUNEL) method was performed with the TUNEL apoptosis kit direct (Beyotime Institute of Biotechnology) as described previously (26). Briefly, gastric mucosal cells were counterstained with 2-(4-amidinophenyl)-1H-indole-6-carboxamidine dihydrochloride (DAPI) (Beyotime Institute of Biotechnology) to label the DNA of all nuclei, and fragmented DNA was end-labeled with fluoroscein isothiocyanate (FITC)-labeled dUTP using terminal transferase. The gastric mucosa was then observed using a fluorescence microscope. Sections that were pretreated with DNase I to nick all DNA served as positive controls. For negative controls, dUTP was omitted, resulting in uniformly negative staining. Ten optical fields, 500-1000 cells, were counted in each slide under high power (x400) microscopy, and the number of positive cells per field was expressed as the apoptotic index. These experiments were performed in triplicate with 6 mice/group/experiment.

Measurement of caspase-3 activity. Activity of caspase-3 was detected using a commercially available caspase-3 activity kit (Beyotime Institute of Biotechnology) with Ac-DEVD-pNA as the colorimetrically specific substrate. In brief, gastric mucosal samples ( $n=6$ for each treatment) were weighed and homogenized in lysis buffer containing $10 \mathrm{mM} / 1 \mathrm{HEPES} / \mathrm{KOH}$ (pH 7.2), 2 mM/l EDTA, 0.1\% CHAPS, 5 mM/1 dithiothreitol, $1 \mathrm{mM} / 1$ phenylmethyl-sulfonylfluoride, $10 \mu \mathrm{g} / \mathrm{ml}$ aprotinin and $20 \mu \mathrm{g} / \mathrm{ml}$ leupeptin. The lysate was centrifuged at $20,000 \mathrm{x} \mathrm{g}$ for $10 \mathrm{~min}$ at $4^{\circ} \mathrm{C}$, and supernatants were incubated for $7 \mathrm{~h}$ at $37^{\circ} \mathrm{C}$ with $10 \mu \mathrm{l}$ caspase-3 substrate (Ac-DEVD-pNA, $2 \mathrm{mM} / \mathrm{l}$ ). Substrate cleavage was measured with a spectrofluorometer at $405 \mathrm{~nm}$ and was corrected as enzyme activity according to standard curve content in the lysate. The activity of caspase- 3 was expressed as values of enzyme activity compared with the control $(27,28)$.

Immunohistochemical analysis. Antibodies for FoxO1/FKHR (no. 9462, lot 2), FoxO3A/FKHRL1 (no. 9467, lot 4), FoxO4/ AFX (no. 9472, lot 1) and total PKB/Akt (no 9292, lot 1) were purchased from Cell Signaling Technology (Beverly, MA, USA). Antibodies for PTEN (no. sc-9145, lot C0707) were obtained from Santa Cruz Biotechnology, Inc. (Santa Cruz, CA, USA). Antibodies for IGF-1 (BA0939) were obtained from Boster Bio-engineering (Wuhan, China). ABC kits were obtained from BioGenex Laboratories, Inc. (San Ramon, CA, USA) and 3,3'-diaminobenzidine tetrachloride (DAB) was purchased from Sigma Chemical Co. (St. Louis, MO, USA). All other chemicals were purchased commercially and were of reagent grade. 
Table I. Primers used for real-time PCR analysis.

\begin{tabular}{|c|c|c|c|}
\hline $\begin{array}{l}\text { Gene and sequence } \\
\text { reference (GenBank no.) }\end{array}$ & Primer sequence & $\begin{array}{l}\text { Size of PCR } \\
\text { product (bp) }\end{array}$ & $\begin{array}{c}\text { Annealing } \\
\text { temperature }\left({ }^{\circ} \mathrm{C}\right)\end{array}$ \\
\hline HPRT (X62085) & $\begin{array}{l}\text { F: 5'-AGTGATGATGAACCAGGTTA-3' } \\
\text { R: 5'-ATTATAGTCAAGGGCATATC-3' }\end{array}$ & 556 & 58.0 \\
\hline IGF-1 (BC086374) & $\begin{array}{l}\text { F: 5'-TGGTGGACGCTCTTCAGTTC-3' } \\
\text { R: 5'-GCTTCAGCGGAGCACAGTAC-3 }\end{array}$ & 168 & 58.0 \\
\hline PTEN (NM031606) & $\begin{array}{l}\text { F: 5'-AGCGTGCGGATAATGACAAG-3' } \\
\text { R: 5'-GGATTTGATGGCTCCTCTACTG-3' }\end{array}$ & 151 & 56.0 \\
\hline Akt-1 (NM033230) & $\begin{array}{l}\text { F: 5'-TAGGCATCCCTTCCTTACAG-3' } \\
\text { R: 5'-GCCCGAAGTCCGTTATCT-3' }\end{array}$ & 269 & 58.0 \\
\hline Akt-2 (NM017093) & $\begin{array}{l}\text { F: 5'-GAGCCGAGTCCTACAGAATACC-3' } \\
\text { R: 5'-GGCCATCTTTGTCCAGCATA-3' }\end{array}$ & 263 & 58.0 \\
\hline Akt-3 (NM031575) & $\begin{array}{l}\text { F: 5'-AACGACCAAAGCCAAATACA-3' } \\
\text { R: 5'-CCCCATTAACATATTCCATCAC-3' }\end{array}$ & 498 & 58.0 \\
\hline FoxO1 (NM001191846) & $\begin{array}{l}\text { F: 5'-CGTCCTCGAACCAGCTCAA-3' } \\
\text { R: 5'-TTGGCGGTGCAAATGAATAG-3' }\end{array}$ & 292 & 57.4 \\
\hline FoxO3a (NM001106395) & $\begin{array}{l}\text { F: 5'-TTCGCAACGACCCAATGA-3' } \\
\text { R: 5'-TCCAAGCTCCCATTGAACAT-3' }\end{array}$ & 331 & 57.4 \\
\hline Fox04 (NM001106943) & $\begin{array}{l}\text { F: 5'-GGTGCCCTACTTCAAGGACAA-3' } \\
\text { R: 5'-ATCGGGGTTCAGCATCCA-3' }\end{array}$ & 148 & 58.0 \\
\hline
\end{tabular}

After transferral through a graded series of alcohol and xylene, gastric mucosal samples were embedded in paraffin and sectioned $(7 \mu \mathrm{m})$. The sample sections were mounted on slides and processed for immunohistochemical analysis, which was conducted using a protocol similar to the method used in our previous reports (29). Briefly, sections were incubated overnight at room temperature with a polyclonal rabbit immunoaffinitypurified antiserum directed against IGF-1 (1:200), PTEN (1:400), total Akt (1:400); and FoxO1 (1:400), FoxO3a (1:400) and FoxO4 proteins (1:500). The specific protein immunoreactivity was visualized with an Elite $\mathrm{ABC}$ kit and $0.05 \% \mathrm{DAB}$ in $10 \mathrm{mM}$ PBS-buffered saline containing $0.01 \% \mathrm{H}_{2} \mathrm{O}_{2}$ for $5 \mathrm{~min}$. Specificity of the antibody was examined using normal rabbit serum (NRS) instead of the primary antibody. In order to identify structural components and cell morphology, the sections were counter-stained with hematoxylin and mounted with coverslips. Relative levels of immunostaining between animals and cell types were repeated at least four times and evaluated by three independent observers.

Total-RNA isolation and reverse transcription. Gastric mucosal samples were collected and stored in liquid nitrogen until the time of RNA isolation. Total-RNA was isolated after homogenizing gastric mucosa in TRIzol ${ }^{\circledR}$ reagent (Invitrogen, USA) using the manufacturer's protocol. RNA quality was evaluated by examining a portion on a RNA gel. Bands of $18 \mathrm{~S}$ and $28 \mathrm{~S}$ were clear, and there was little smearing, indicating that the quality was acceptable. However, the $18 \mathrm{~S}$ band was not as dark as expected, suggesting that some slight RNA degradation had occurred.
Reverse transcription reactions (RT) were performed using RT reagent kits with gDNA Eraser (Takara, China). The total reaction volume of $20 \mu \mathrm{l}$ contained $2 \mu 1$ 5X gDNA Eraser buffer, $1 \mu \mathrm{l}$ gDNA Eraser, $1 \mu \mathrm{g}$ total-RNA, $4 \mu 1$ 5X RT buffer, $1 \mu 1 \mathrm{RT}$ enzyme mix, $1 \mu \mathrm{l}$ RT primer mix and sufficient nuclease-free $\mathrm{H}_{2} \mathrm{O}$. The RT reaction was carried out at $42^{\circ} \mathrm{C}$ for $2 \mathrm{~min}, 37^{\circ} \mathrm{C}$ for $15 \mathrm{~min}$, followed by a denaturation step at $85^{\circ} \mathrm{C}$ for $15 \mathrm{sec}$ and cooling on ice.

Real-time PCR analysis of gene expression. Quantification of all transcripts was performed by real-time quantitative PCR using the ABI 7300 PRISM system (Applied Biosystems, USA). PCR products for 9 genes (IGF-1, PTEN, Akt-1, Akt-2, Akt-3, FoxOl, FoxO3a, FoxO4 and HPRT) were detected by SYBR Green chemistry. The sequences and GenBank accession nos. of the primer sets used for amplification of the target genes are presented in Table I. PCR reactions were run in triplicates in a total volume of $20 \mu \mathrm{l}$ (consisting of SYBR Premix Ex Taq, ROX Reference Dye, $200 \mathrm{nM}$ each of the sequence-specific primers and $100 \mathrm{ng}$ equivalent of cDNA). The amplification conditions were as follows: DNA polymerase activation at $95^{\circ} \mathrm{C}$ for $30 \mathrm{sec}$, followed by 40 amplification cycles at $95^{\circ} \mathrm{C}$ for $5 \mathrm{sec}$, and $60^{\circ} \mathrm{C}$ for $31 \mathrm{sec}$. At the end of the amplification cycles, a melting curve analysis was performed to verify specific amplification.

The comparative CT method was used for relative quantification of target gene expression levels (ABI PRISM Sequence Detection System, Applied Biosystems). The quantity of each measured cDNA sample was normalized to the endogenous gene HPRT (a housekeeping gene), and all samples were 


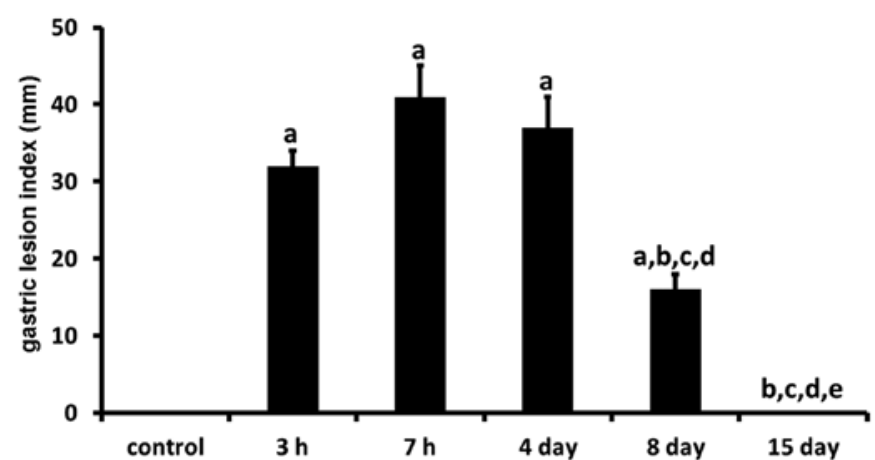

Figure 1. Effects of various time durations of WRS and healing on the gastric lesion index in rats. Data represent the means \pm SEM. ${ }^{a} \mathrm{P}<0.05$ vs. control group; ${ }^{b} \mathrm{P}<0.05$ vs. 3 -h WRS group; ${ }^{\mathrm{c}} \mathrm{P}<0.05$ vs. 7 -h WRS group; ${ }^{\mathrm{d}} \mathrm{P}<0.05$ vs. 4 days after WRS group; ${ }^{e} \mathrm{P}<0.05$ vs. 8 days after WRS group.

measured in triplicate. The mean values of the replicate wells run for each sample were calculated and divided by HPRT to obtain a normalized value for each transcript (30).

Statistical analysis. Statistical analyses were performed by using SPSS 17.0. Values are expressed as the means \pm standard error of the mean (SEM). The data were analyzed using a one-way analysis of variance (ANOVA) and with Fisher's protected least significant difference (LSD) tests. $\mathrm{P}<0.05$ was considered to indicate a statistically significant result. All experiments were repeated at least 3 times, and representative data are shown.

\section{Results}

Effects of various time durations of WRS and healing on the $U I$ in rats. In the evaluation of WRS-induced gastric mucosal injury in rats $(n=6)$, the total length of lesions in the stomach was expressed as the morphologic index of gastric ulcers (Fig. 1). In contrast to the normal appearance of the gastric mucosa in control rats, numerous hemorrhagic lesions were observed in the gastric mucosa of rats subjected to WRS. The number of gastric mucosal lesions increased time-dependently in the gastric mucosa of rats exposed to WRS for various time durations (0, 3 and $7 \mathrm{~h}$ ). Exposure to $3 \mathrm{~h}$ WRS resulted in the formation of gastric mucosal lesions. When the WRS was extended up to $7 \mathrm{~h}$, the number of gastric mucosal lesions was higher than that at $3 \mathrm{~h}(\mathrm{P}>0.05)$. In the gastric mucosa, the lengths of lesions were $32.2 \pm 2.7 \mathrm{~mm}$ after $3 \mathrm{~h}$ of WRS and $41.6 \pm 4.9 \mathrm{~mm}$ after $7 \mathrm{~h}$ of WRS.

In contrast, during the healing of gastric lesions, the number of gastric lesions showed a progressive decrease at 4,8 and 15 days following $7 \mathrm{~h}$ of WRS. At Day 8, the number of gastric lesions was significantly less than that at Day $4(\mathrm{P}<0.05)$. In the gastric mucosa, the lengths of lesions were $37.2 \pm 4.3 \mathrm{~mm}$ at Day 4 and 16.6 $\pm 2.4 \mathrm{~mm}$ at Day 8. No gastric lesions were observed in the gastric mucosa of rats at Day 15 .

Effect of WRS on apoptosis in the gastric mucosa. Gastric tissue sections were stained using the TUNEL method to determine the quantity and distribution of apoptotic cells as well as nuclear condensation and fragmentation $(n=5)$. Tissue sections exposed to DNase I, which causes DNA fragmenta-

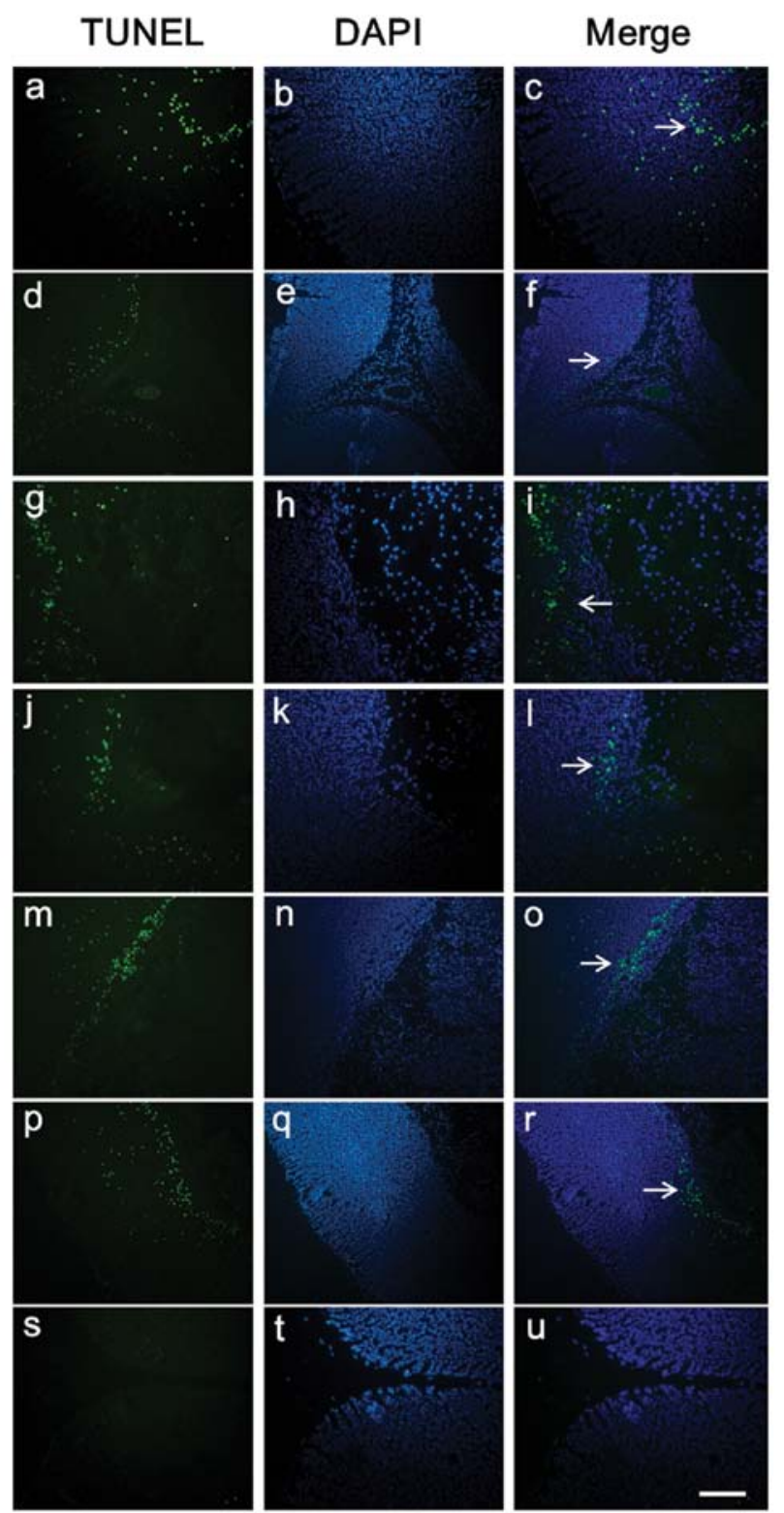

Figure 2. Effect of WRS on the number of apoptotic cells in the gastric mucosa. Tissue sections of rat gastric mucosa were stained using the TUNEL method, and sections were then counterstained with DAPI to label all nuclei Blue color, DAPI-stained nuclei. Green color, TUNEL-positive cells. Tissue samples from groups: (a-c) non-WRS, (d-f) $3 \mathrm{~h}$ of WRS, (g-i) $7 \mathrm{~h}$ of WRS (j-1) 4 days after WRS, (m-o) 8 days after WRS and (p-r) 15 days after WRS (s-u) Sections stained by the previous procedure but without use of the TdT enzyme showed no staining and were used as negative controls. $\rightarrow$, Muscularis mucosa. Bar, $50 \mu \mathrm{m}$.

tion, showed intense staining of all nuclei and were used as positive controls for the TUNEL method (data not shown). Sections stained using the previous procedure but without the use of the TdT enzyme, showed no staining and were used as negative controls (Fig. $2 \mathrm{~s}-\mathrm{u}$ ). In the gastric mucosa of the non-WRS rats, little labeling at the mucosal layer close to the muscularis mucosa was found (Fig. 2a-c). In the gastric mucosa of rats subjected to WRS, many apoptotic cells were observed throughout the entire thickness of the mucosal layer and muscularis mucosa (Fig. 2d-r). Furthermore, the number of apoptotic cells in the gastric mucosa of the rats subjected to 

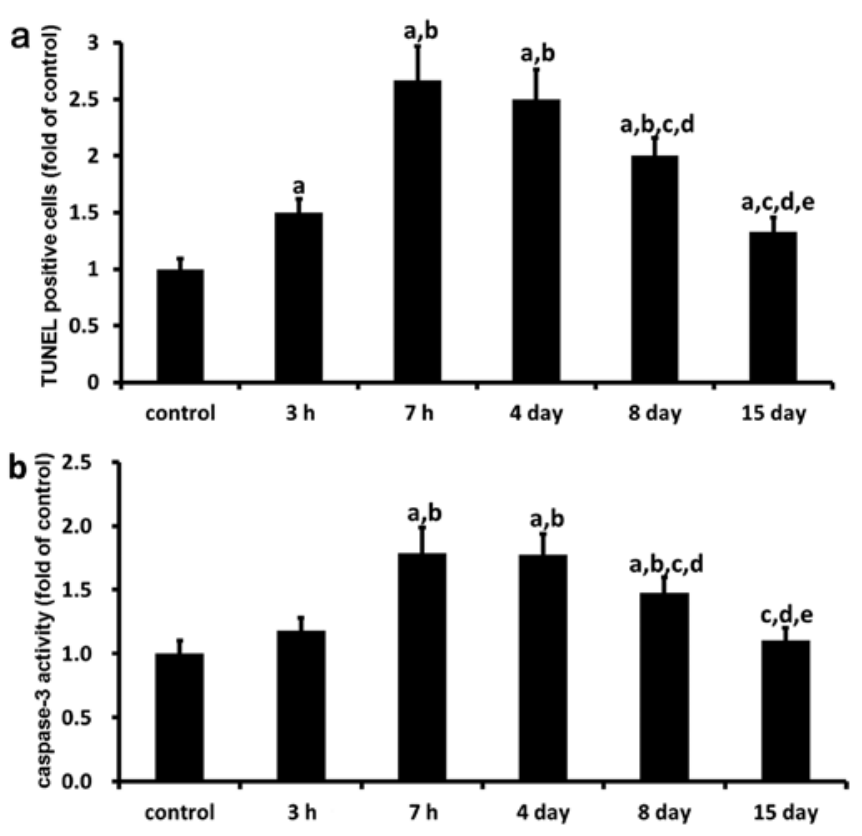

Figure 3. Effect of WRS on (a) the number of TUNEL-positive cells in gastric mucosa and (b) caspase-3 activity in gastric mucosa in rats. Number of nuclei staining positive for (a) TUNEL and (b) gastric mucosa caspase-3 activity are shown. Data (fold of control) represent the means \pm SEM. ${ }^{a} \mathrm{P}<0.05$ vs. control group; ${ }^{b} \mathrm{P}<0.05$ vs. 3 -h WRS group; ${ }^{\mathrm{c}} \mathrm{P}<0.05$ vs. 7 -h WRS group; ${ }^{\mathrm{d}} \mathrm{P}<0.05$ vs. 4 days after WRS group; ${ }^{\mathrm{e}} \mathrm{P}<0.05$ vs. 8 days after WRS group.

3 and $7 \mathrm{~h}$ of WRS were significantly increased by $50(\mathrm{P}<0.05)$ and $167 \%(\mathrm{P}<0.05)$, respectively, compared with that in the control group (Fig. 3a). In addition, from Days 14 and 15 after $7 \mathrm{~h}$ of WRS, the number of apoptotic cells in the gastric mucosa decreased gradually (Fig. 3a). By Day 8 following $7 \mathrm{~h}$ of WRS, the number of apoptotic cells in the gastric mucosa were significantly decreased by $37(\mathrm{P}<0.05)$ and $30 \%(\mathrm{P}<0.05)$ respectively, compared to the number in the group subjected to $7 \mathrm{~h}$ of WRS or Day 4. Nevertheless, no significant difference between the 15-day group and the control group was observed.

In order to reconfirm the cell apoptosis in gastric lesion development and healing, caspase-3 activity in the gastric ulcer margin of rats was detected by colorimetric analysis $(n=6)$. Caspase-3 activity in the gastric ulcer margin after 3 and $7 \mathrm{~h}$ of WRS were also time-dependently enhanced by 18 and $79 \%(\mathrm{P}<0.05)$, compared with the control group (Fig. 3b). However, at Days 4, 8 and 15 after 7 h of WRS, the caspase-3 activity decreased gradually with time, compared with the 7-h WRS group. At 8 days after $7 \mathrm{~h}$ of WRS, the caspase-3 activity was significantly decreased by $31(\mathrm{P}<0.05)$ and $30 \%$ $(\mathrm{P}<0.05)$ respectively, compared with the $7-\mathrm{h}$ WRS group and the group at 4 days $(\mathrm{P}<0.05)$. There was no significant difference between the 15-day group and the control group.

Immunohistochemical localization of IGF-1, PTEN, total Akt, FoxO1, FoxO3a and FoxO4 in the gastric mucosa of rats after WRS. To assess the localization of IGF-1, PTEN, total Akt, FoxO1, FoxO3a and FoxO4 in rat gastric ulcers $(n=6)$, sections from normal and ulcerated gastric mucosa were stained with specific antibodies against these proteins. In normal rat gastric mucosa, PTEN (Fig. 4e), total Akt (Fig. 4h), and
FoxO1 (Fig. 4k) were found mainly in the cellular cytoplasm of the fundic glands in lamina propria close to the muscularis mucosa. The results indicated that strong staining of IGF-1 (Fig. 4b), FoxO3a (Fig. 4n) and FoxO4 (Fig. 4q) in the gastric mucosa was primarily concentrated in the cell cytoplasm of the fundic glands in whole lamina propria. However, in rat gastric ulcers, IGF-1 (Fig. 4a-c), total Akt (Fig. 4g-i), FoxO3a (Fig. 4m-o) and FoxO4 (Fig. 4p-r) were localized proximal to the base of the ulcer margin and were also present in the granulation tissue of gastric ulcers. The expression patterns of PTEN (Fig. 4d-f) and FoxO1 (Fig. 4j-1) did not change in the rat gastric ulcers, compared with the control rats. No marked staining of PTEN and FoxO1 was found around the ulcer margin and granulation tissue.

Relative expression of IGF-1, PTEN, Akt-1, Akt-2, Akt-3, FoxO1, FoxO3a and FoxO4 in the gastric mucosa of rats after WRS. Expression levels of selected genes were analyzed using real-time PCR $(n=6)$. Amplification products were identified by melting curve profile analysis and confirmed by gel electrophoresis and sequencing. The data showed the relative transcript of each target gene normalized to HPRT. The real-time RT-PCR analysis of a 168 bp (transcript) of $I G F-1$, a 151 bp of PTEN, a 269 bp of Akt-1, a 263 bp of Akt-2, a 498 bp of Akt-3, a 292 bp of FoxOl, a 331 bp of FoxO3a, a 148 bp of FoxO4, and a 556 bp of HPRT is shown in Fig. 5. All selected genes were transcriptionally active. In the rat gastric ulcers, mRNA transcript levels of $I G F-1$ (Fig. 5a), Akt-2 (Fig. 5b) and FoxO4 (Fig. 5c) were upregulated in the gastric ulcer margin, with a peak 8 days after $7 \mathrm{~h}$ of WRS. The mRNA transcript levels of $A k t-2$ returned to near baseline levels at 15 days following $7 \mathrm{~h}$ of WRS. However, the mRNA transcript levels of IGF-1 and FoxO4 in the WRS groups were still significant higher than those in the non-WRS group $(\mathrm{P}<0.05)$. Similarly, mRNA transcript levels of PTEN (Fig. 5a), Akt-1 (Fig. 5b) and FoxO3a (Fig. 5c) were also upregulated in the gastric ulcer margin, with a peak at 4 days following $7 \mathrm{~h}$ of WRS, and returned to near baseline levels at 15 days following $7 \mathrm{~h}$ of WRS. In addition, the results showed that Akt-3 (Fig. 5b) and FoxOl (Fig. 5c) mRNA transcript levels in rats subjected to WRS had no significant difference during the development and healing of WRS-induced gastric ulcers.

\section{Discussion}

The WRS rat has long been used as a model animal of gastric mucosal lesions (12). As shown in the present study, in the evaluation of WRS-induced gastric mucosal injury in rats, the gastric mucosa exposed to WRS of various durations lasting 0,3 and $7 \mathrm{~h}$, time-dependently increased the number of gastric mucosal lesions. Moreover, in the healing of WRS-induced gastric ulcers, the number of gastric lesions showed a progressive decrease at 4,8 and 15 days after $7 \mathrm{~h}$ of WRS. These results are consistent with previous studies (12,26,31-34), suggesting that the rat gastric ulcer model is well established.

Apoptosis is normally observed in the gastrointestinal tract and plays an important role in the maintenance of normal gastrointestinal homeostasis and mucosal integrity (35). Recent studies have demonstrated that apoptosis is critically involved in gastric ulceration $24 \mathrm{~h}$ after ulcer induction 

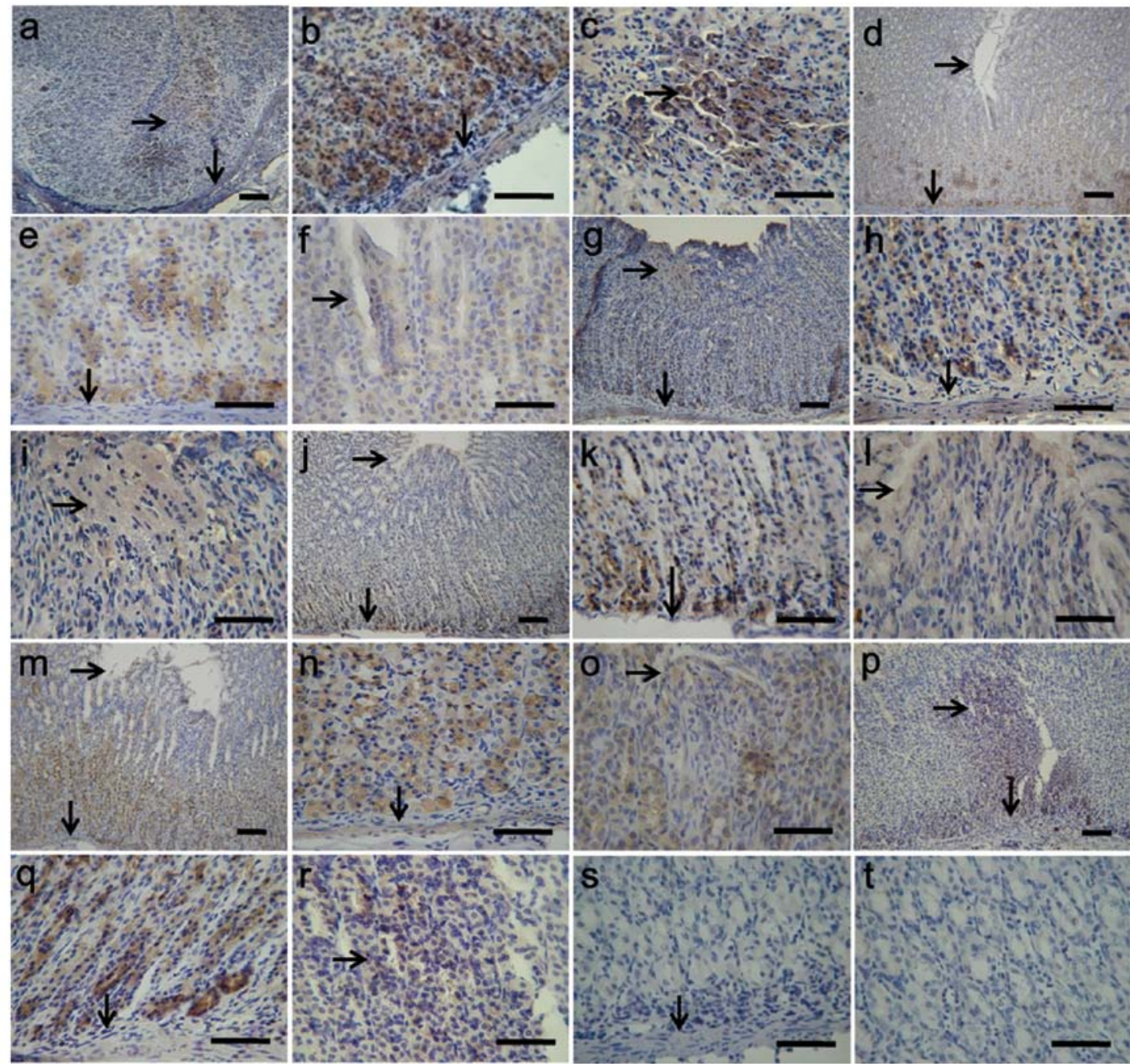

Figure 4. Immunohistochemical localization of IGF-1, PTEN, total Akt, FoxO1, FoxO3a and FoxO4 in the gastric mucosa of rats after WRS. The immunohistochemical signals appear brown and the counterstained background appears blue in color. The figures indicate immunohistochemical localization of (a-c) IGF-1, (d-f) PTEN, (g-i) total Akt, (j-1) FoxO1, (m-o) FoxO3a and (p-r) FoxO4. In the control sections, normal albumin bovine was used instead of the primary antibody (s and t)., , Muscularis mucosa; $\rightarrow$, gastric mucosal ulcer. Bar, $50 \mu \mathrm{m}$.

(36,37). Caspases are causative enzymes that induce apoptosis and are always present in intact cells, playing important roles in the pathogenesis of tissue injury by activating neutrophils. Nevertheless, all known stimuli that induce apoptosis initiate events that culminate in caspase activation (38). Previous reports showed that IGF-1 and capsaicin administration to rats markedly reduced WRS-induced gastric mucosal injury by inhibiting gastric accumulation of neutrophils through inhibition of caspase- 3 activation $(22,39)$. In the present study, we systematically investigated apoptosis in the development and healing of WRS-induced gastric ulcers. We found that WRS induced increases in both gastric caspase- 3 activity and the number of TUNEL-positive cells during the development of gastric ulcers. Thereafter, during the healing of gastric ulcers, both gastric caspase-3 activity and the number of TUNELpositive cells decreased slowly in 15 days. This suggests that apoptosis plays a role in the development and healing of WRS-induced gastric ulcers.

The IGF-1/PTEN/Akt/FoxO signaling pathway plays critical roles in the regulation of cell survival, growth, differ- entiation and migration in many cell types and tissues $(3,40)$. To confirm whether the IGF-1/PTEN/Akt/FoxO signaling pathway plays a critical role in the development and healing of WRS-induced gastric ulcers, localization and expression of IGF-1, PTEN, Akt and FoxO proteins were evaluated in the present study. The results revealed that IGF-1 was localized proximal to the base of the ulcer margin and was also present in the granulation tissue of gastric ulcers. Meanwhile, mRNA transcript levels of $I G F-1$ were upregulated in the gastric ulcers, with a peak 8 days after $7 \mathrm{~h}$ of WRS. In the gastrointestinal tract, IGF-1 is secreted by salivary and other exocrine glands (41). It has been reported that gastric ulceration triggered an $\sim 3$-fold increase in IGF-1 expression in epithelial cells of the ulcer margins (17). Additionally, studies using diabetic and arthritic rat models have demonstrated a delay in gastric ulcer healing attributed to a decrease in IGF-1 mRNA in the gastric mucosa $(42,43)$. Subsequently, injection of exogenous IGF-1 to these diabetic and arthritic rats was found to accelerate ulcer healing. Moreover, direct injection of IGF-1 into the ulcers was also shown to accelerate the healing 

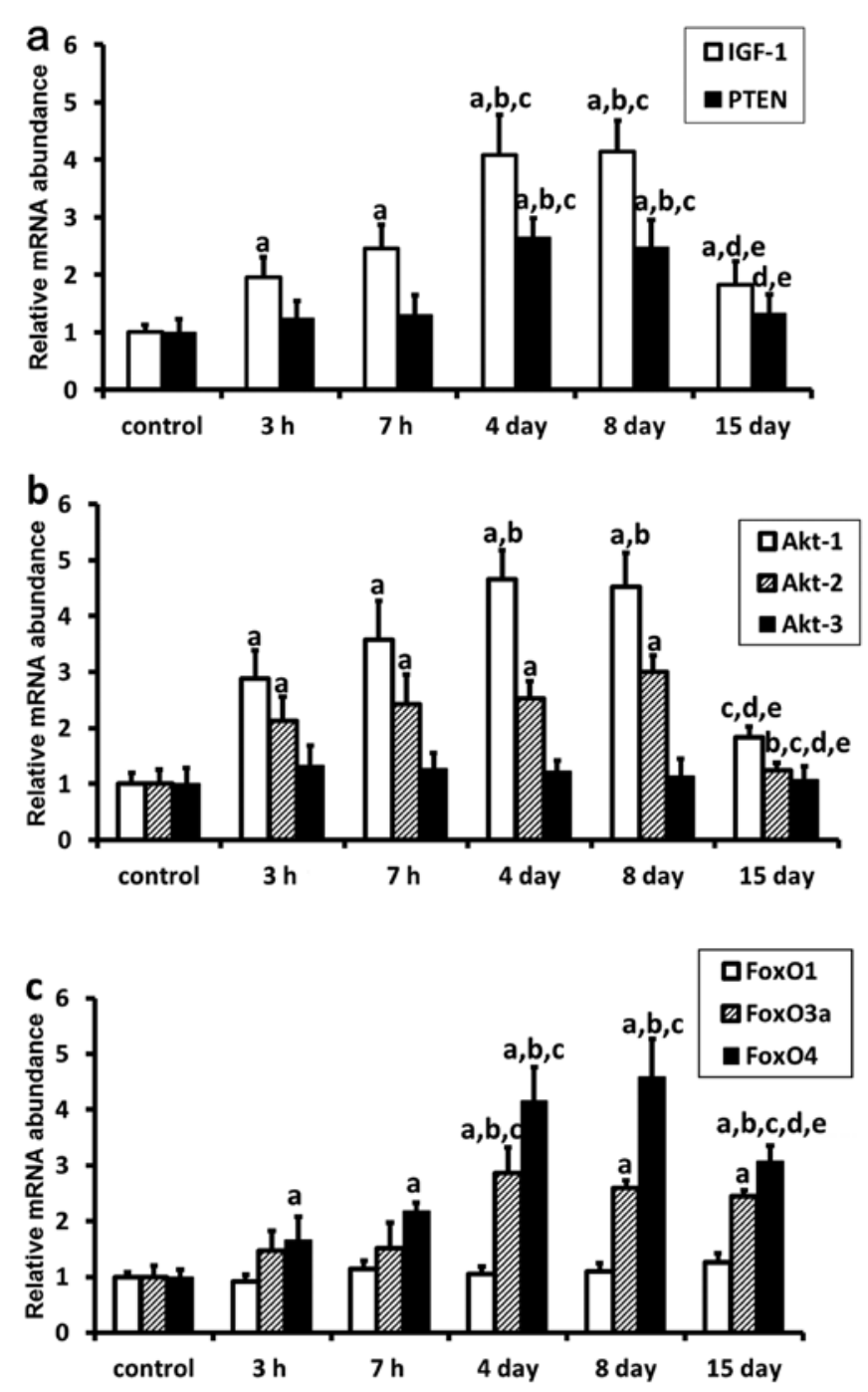

Figure 5. Relative expression of IGF-1, PTEN, Akt-1, Akt-2, Akt-3, FoxO1, FoxO3a and FoxO4 in the gastric mucosa of rats after WRS. (a) IGF-1 and PTEN; (b) Akt-1, Akt-2 and Akt-3; (c) FoxO1, FoxO3a and FoxO4. Data represent the means \pm SEM. ${ }^{a} \mathrm{P}<0.05$ vs. control group; ${ }^{b} \mathrm{P}<0.05$ vs. $3-\mathrm{h}$ WRS group; ${ }^{\mathrm{c}} \mathrm{P}<0.05$ vs. 7-h WRS group; ${ }^{\mathrm{d}} \mathrm{P}<0.05$ vs. 4 days after WRS group; ${ }^{\mathrm{e}} \mathrm{P}<0.05$ vs. 8 days after WRS group.

of cryo-induced rat gastric ulcers (44). Under in vitro conditions, exogenous IGF-1 has been shown to promote migration and proliferation in intrahepatic biliary epithelial cells and in a wounded monolayer of rabbit gastric epithelial cells $(20,45)$. Related findings revealed that IGF-1 is upregulated in injured skin, bone and brain (17). Accordingly, our results suggest that IGF-1 plays a key role in combating ulcers through regulation of its downstream genes as noted during the development and healing of gastric ulcers.

In addition, Nguyen et al (17) found that upregulation of IGF-1 in gastric ulcer margins enhanced gastric ulcer healing by promoting cell re-epithelialization, proliferation and COX-2 expression via the PI3K pathway. Furthermore, it was also reported that IGF-1 reduced WRS-induced gastric mucosal injury by inhibiting gastric accumulation of neutrophils through inhibition of caspase-3 activation by PI3K/Akt signaling (22). In the present study, total Akt protein was localized around gastric ulcer margins and was also present in granulation tissue. In addition, gastric ulceration triggered increases in Akt-1 and Akt-2 mRNA expression during the development and healing of gastric ulcers. mRNA transcript levels of Akt-3 did not change significantly during the development and healing of WRS-induced gastric ulcers. As described above, these results suggest that Akt-1 and Akt-2 participate in the inhibition of caspase- 3 activation in rat gastric ulcers.

The PTEN gene is a tumor suppressor that is frequently deleted or mutated in human cancers, and which controls Akt signaling. Its downstream targets are responsible for regulating many physiologically and pathologically significant processes, such as cellular proliferation, survival, growth and motility (8). Results of the present study found that the localization pattern of PTEN did not change in rat gastric ulcers, compared with normal rats. It was observed mainly in the cell cytoplasm of the fundic glands in the lamina propria close to the muscularis mucosa. No marked staining of PTEN was noted around the ulcer margins and granulation tissue. mRNA transcript levels of PTEN were also upregulated in gastric ulcer margins, achieving a peak 4 days following $7 \mathrm{~h}$ of WRS, and returned to a near baseline level at Day 15 following $7 \mathrm{~h}$ of WRS. Many researchers have investigated PTEN in gastric cancer (46-48). In particular, Wang et al (47) revealed that caspase-3 activity was related to upregulation of PTEN in human gastric cancer MGC-803 cells. In accordance with our results, PTEN may be involved in the regulation of cell apoptosis by Akt signaling.

In control rats, strong staining of FoxO3a and FoxO4 in the gastric mucosa was primarily concentrated in the cellular cytoplasm of the fundic glands in the whole lamina propria. In rat gastric ulcers, FoxO3a and FoxO4 were localized proximal to the base of the ulcer margins and were also present in the granulation tissue of gastric ulcers. Furthermore, mRNA transcript levels of FoxO3a and $\mathrm{FoxO}_{4}$ were upregulated in gastric ulcers, reaching a peak between Day 4 and 8 following $7 \mathrm{~h}$ of WRS. FoxO1 was localized in the cellular cytoplasm of the fundic glands close to the muscularis mucosa in normal gastric mucosa. However, its staining was not observed around the mucosal ulcer. mRNA transcript levels of FoxOl did not change siginificantly during the development and healing of WRS-induced gastric ulcers.

FoxO1, FoxO3a and FoxO4 are all downstream effectors of the IGF-1/PTEN/Akt pathway. These FoxO proteins participate in a growing number of physiologic processes including cell proliferation, apoptosis, stress resistance, differentiation and metabolism (49). The present results were consistent with our previous studies $(23,24)$ and suggest that FoxO3a and FoxO4 are the primary forkhead transcriptional factors localized to the gastrointestinal tracts. Liu et al (50) showed that FoxO1 mRNA was expressed at lower levels in the duodenum subcutaneous adipose tissue and pancreas than in other tissues of pigs. In addition, phosphorylation of FoxO proteins by $\mathrm{PKB}$ results in cytoplasmic retention and inactivation, which consequently inhibits the expression of FoxO-regulated genes that control the cell cycle, cell death and cell metabolism. The shuttling of FoxOs between the cytoplasm and nucleus is a key step in apoptosis (11). FoxO3a and FoxO4 may thereby be involved in the development and healing of WRS-induced gastric ulcers, which, in part, are associated with the regulation of apoptosis. 
In conclusion, these observations raise the possibility that the IGF-1/PTEN/Akt/FoxO signaling pathway plays certain role(s) in protecting against ulcers through the regulation of cellular apoptosis as observed during the development and healing of rat gastric ulcers.

\section{Acknowledgements}

This study was supported by the National Nature Science Foundation of China (no. 31172206) and a Grant-in-Aid for the Innovative Training of Doctoral Students in Jiangsu Province of China (CXLX11-0699).

\section{References}

1. Castrillon DH, Miao L, Kollipara R, Horner JW and DePinho RA: Suppression of ovarian follicle activation in mice by the transcription factor Foxo3a. Science 301: 215-218, 2003.

2. Carnero A, Blanco-Aparicio C, Renner O, Link W and Leal JF: The PTEN/PI3K/AKT signalling pathway in cancer, therapeutic implications. Curr Cancer Drug Targets 8: 187-198, 2008.

3. Reddy P, Liu L, Adhikari D, et al: Oocyte-specific deletion of Pten causes premature activation of the primordial follicle pool Science 319: 611-613, 2008.

4. Carroll PV: Treatment with growth hormone and insulin-like growth factor-I in critical illness. Best Pract Res Clin Endocrinol Metab 15: 435-451, 2001.

5. Song G, Ouyang G and Bao S: The activation of Akt/PKB signaling pathway and cell survival. J Cell Mol Med 9: 59-71, 2005.

6. Cully M, You H, Levine AJ and Mak TW: Beyond PTEN mutations: the PI3K pathway as an integrator of multiple inputs during tumorigenesis. Nat Rev Cancer 6: 184-192, 2006.

7. Fresno Vara JA, Casado E, de Castro J, Cejas P, Belda-Iniesta C and Gonzalez-Baron M: PI3K/Akt signalling pathway and cancer. Cancer Treat Rev 30: 193-204, 2004.

8. Leslie NR and Downes CP: PTEN function: how normal cells control it and tumour cells lose it. Biochem J 382: 1-11, 2004.

9. Cross DA, Alessi DR, Cohen P, Andjelkovich M and Hemmings BA: Inhibition of glycogen synthase kinase- 3 by insulin mediated by protein kinase B. Nature 378: 785-789, 1995.

10. Sengupta A, Molkentin JD, Paik JH, DePinho RA and Yutzey KE: FoxO transcription factors promote cardiomyocyte survival upon induction of oxidative stress. J Biol Chem 286 : 7468-7478, 2011.

11. Burgering BM and Kops GJ: Cell cycle and death control: long live Forkheads. Trends Biochem Sci 27: 352-360, 2002.

12. Adachi M, Horiuchi G, Ikematsu N, et al: Intragastrically administered lysophosphatidic acids protect against gastric ulcer in rats under water-immersion restraint stress. Dig Dis Sci 56: 2252-2261, 2011.

13. Yi SX, Peng Y, Chang XR, Peng N, Yan J and Lin YP: Effect of pre-moxibustion on apoptosis and proliferation of gastric mucosa cells. World J Gastroenterol 13: 2174-2178, 2007.

14. Nie SN, Qian XM, Wu XH, et al: Role of TFF in healing of stress-induced gastric lesions. World J Gastroenterol 9: 17721776,2003

15. Li YM, Lu GM, Zou XP, Li ZS, Peng GY and Fang DC: Dynamic functional and ultrastructural changes of gastric parietal cells induced by water immersion-restraint stress in rats. World J Gastroenterol 12: 3368-3372, 2006.

16. Jiang P, Chang L, Pan CS, Qi YF and Tang CS: Protective role of metallothionein in stress-induced gastric ulcer in rats. World $\mathrm{J}$ Gastroenterol 11: 2739-2743, 2005.

17. Nguyen T, Chai J, Li A, Akahoshi T, Tanigawa $\mathrm{T}$ and Tarnawski AS: Novel roles of local insulin-like growth factor-1 activation in gastric ulcer healing: promotes actin polymerization, cell proliferation, re-epithelialization, and induces cyclooxygenase-2 in a phosphatidylinositol 3-kinase-dependent manner. Am J Pathol 170: 1219-1228, 2007.

18. Harada N, Okajima K, Kurihara H and Nakagata N: Stimulation of sensory neurons by capsaicin increases tissue levels of IGF-I, thereby reducing reperfusion-induced apoptosis in mice. Neuropharmacology 52: 1303-1311, 2007.
19. Daemen MA, van 't Veer C, Denecker G, et al: Inhibition of apoptosis induced by ischemia-reperfusion prevents inflammation. J Clin Invest 104: 541-549, 1999.

20. Watanabe S, Wang XE, Hirose M, et al: Insulin-like growth factor I plays a role in gastric wound healing: evidence using a zinc derivative, polaprezinc, and an in vitro rabbit wound repair model. Aliment Pharmacol Ther 12: 1131-1138, 1998.

21. Nie SN, Sun HC, Wu XH and Qian XM: Cyclooxygenase 2, pS2, inducible nitric oxide synthase and transforming growth factor alpha in gastric adaptation to stress. World J Gastroenterol 10: 3537-3541, 2004

22. Zhao J, Harada N, Sobue K, Katsuya H and Okajima K: Insulinlike growth factor-I reduces stress-induced gastric mucosal injury by inhibiting neutrophil activation in mice. Growth Horm IGF Res 19: 136-145, 2009.

23. Huang P, Zhou ZQ, Huang RH, Zhou B, Wei QW and Shi FX: Age-dependent expression of forkhead box $\mathrm{O}$ proteins in the duodenum of rats. J Zhejiang Univ Sci B 12: 730-735, 2011

24. Zhou ZQ, Wang T, Pan LM, Huang RH and Shi FX: FoxO4 is the main forkhead transcriptional factor localized in the gastrointestinal tracts of pigs. J Zhejiang Univ Sci B 8: 39-44, 2007.

25. Shimozawa N, Okajima K, Harada N, et al: Contribution of sensory neurons to sex difference in the development of stressinduced gastric mucosal injury in mice. Gastroenterology 131: 1826-1834, 2006

26. Kelly KJ, Sandoval RM, Dunn KW, Molitoris BA and Dagher PC: A novel method to determine specificity and sensitivity of the TUNEL reaction in the quantitation of apoptosis. Am J Physiol Cell Physiol 284: C1309-C1318, 2003

27. Wang W, Xu J, Li L, et al: Neuroprotective effect of morroniside on focal cerebral ischemia in rats. Brain Res Bull 83: 196-201, 2010.

28. Song L, Zhang B, Feng Y, Luo X, Wei X and Xiao X: A role for forkhead box A1 in acute lung injury. Inflammation 32: 322-332, 2009.

29. Ding W, Wang W, Zhou B, et al: Formation of primordial follicles and immunolocalization of PTEN, PKB and FOXO3A proteins in the ovaries of fetal and neonatal pigs. J Reprod Dev 56: 162-168, 2010.

30. Liu WM, Shi FX, Lu LZ, et al: Effects of linoleic acid and eicosapentaenoic acid on cell proliferation and lipid-metabolism gene expression in primary duck hepatocytes. Mol Cell Biochem 352: 19-24, 2011.

31. Brzozowski T, Konturek PC, Chlopicki S, et al: Therapeutic potential of 1-methylnicotinamide against acute gastric lesions induced by stress: role of endogenous prostacyclin and sensory nerves. J Pharmacol Exp Ther 326: 105-116, 2008.

32. Brzozowski T, Zwirska-Korczala K, Konturek PC, et al: Role of circadian rhythm and endogenous melatonin in pathogenesis of acute gastric bleeding erosions induced by stress. J Physiol Pharmacol 58 (Suppl 6): S53-S64, 2007.

33. Ceranowicz P, Warzecha Z, Dembinski A, et al: Treatment with ghrelin accelerates the healing of acetic acid-induced gastric and duodenal ulcers in rats. J Physiol Pharmacol 60: 87-98, 2009.

34. Chen CY, Kuo TL, Sheu SY and Kuo TF: Preventive effects of Chinese herb chai-hu-gui-zhi-tang extract on water immersion restraint stress-induced acute gastric ulceration in rats. J Vet Med Sci 72: 679-685, 2010.

35. Sun Z, Wang X, Wallen R, et al: The influence of apoptosis on intestinal barrier integrity in rats. Scand J Gastroenterol 33: 415-422, 1998

36. Konturek PC, Brzozowski T, Duda A, et al: Epidermal growth factor and prostaglandin $\mathrm{E}(2)$ accelerate mucosal recovery from stress-induced gastric lesions via inhibition of apoptosis. J Physiol Paris 95: 361-367, 2001.

37. Konturek PC, Brzozowski T, Konturek SJ, et al: Apoptosis in gastric mucosa with stress-induced gastric ulcers. J Physiol Pharmacol 50: 211-225, 1999.

38. Creagh EM, Conroy $\mathrm{H}$ and Martin SJ: Caspase-activation pathways in apoptosis and immunity. Immunol Rev 193: 10-21, 2003.

39. Harada N, Okajima K, Uchiba M and Katsuragi T: Contribution of capsaicin-sensitive sensory neurons to stress-induced increases in gastric tissue levels of prostaglandins in rats. Am J Physiol Gastrointest Liver Physiol 285: G1214-G1224, 2003.

40. Rabinovsky ED: The multifunctional role of IGF-1 in peripheral nerve regeneration. Neurol Res 26: 204-210, 2004.

41. Chaurasia OP, Marcuard SP and Seidel ER: Insulin-like growth factor I in human gastrointestinal exocrine secretions. Regul Pept 50: $113-119,1994$. 
42. Korolkiewicz RP, Tashima K, Fujita A, Kato S and Takeuchi K Exogenous insulin-like growth factor (IGF)-1 improves the impaired healing of gastric mucosal lesions in diabetic rats. Pharmacol Res 41: 221-229, 2000.

43. Kato S, Tanaka A, Ogawa Y, et al: Effect of polaprezinc on impaired healing of chronic gastric ulcers in adjuvant-induced arthritic rats - role of insulin-like growth factors (IGF)-1. Med Sci Monit 7: 20-25, 2001.

44. Coerper S, Wolf S, von Kiparski S, et al: Insulin-like growth factor I accelerates gastric ulcer healing by stimulating cell proliferation and by inhibiting gastric acid secretion. Scand J Gastroenterol 36: 921-927, 2001.

45. Alvaro D, Metalli VD, Alpini G, et al: The intrahepatic biliary epithelium is a target of the growth hormone/insulin-like growth factor 1 axis. J Hepatol 43: 875-883, 2005.

46. Xiong X, Ren HZ, Li MH, Mei JH, Wen JF and Zheng CL: Down-regulated miRNA-214 induces a cell cycle G1 arrest in gastric cancer cells by up-regulating the PTEN protein. Pathol Oncol Res 17: 931-937, 2011.
47. Wang X, Xie Y and Xiao Q: Lentivirus-mediated RNA interference targeting E2F-1 inhibits human gastric cancer MGC-803 cell growth in vivo. Exp Mol Med 43: 638-645, 2011.

48. Liu X, Guo WJ, Zhang XW, Cai X, Tian S and Li J: Cetuximab enhances the activities of irinotecan on gastric cancer cell lines through downregulating the EGFR pathway upregulated by irinotecan. Cancer Chemother Pharmacol 68: 871-878, 2011.

49. Nakae J, Biggs WH III, Kitamura T, et al: Regulation of insulin action and pancreatic beta-cell function by mutated alleles of the gene encoding forkhead transcription factor Foxol. Nat Genet 32: 245-253, 2002.

50. Liu Y, Wang Y, Shan T, Guo J, Xu C and Liu J: The tissue-specific and developmental expression patterns of the forkhead transcription factor FoxO1 gene in pigs. J Anim Feed Sci 17: 182-190: 2008. 